\title{
Predicting aquatic macrophyte occurrence in soft-water oligotrophic lakes (Pyrenees mountain range)
}

\author{
Cristina PULIDO,${ }^{1 *}$ Joan Lluís RIERA,${ }^{2}$ Enric BALLESTEROS,${ }^{1}$ Eglantine CHAPPUIS, ${ }^{1}$ Esperança GACIA ${ }^{1}$ \\ ${ }^{1}$ Biogeodynamics and Biodiversity Group, Centre d'Estudis Avançats de Blanes (CEAB-CSIC), Accés a la Cala St. Francesc 14, \\ 17300 Blanes; ${ }^{2}$ Departament d'Ecologia, Universitat de Barcelona, Diagonal 643, 08028 Barcelona, Spain \\ *Corresponding author: cpulido@ceab.csic.es
}

\begin{abstract}
Distribution of aquatic macrophytes in lakes is related to geographical, morphological, catchment and water chemistry variables as well as human impacts, which modify the original environment. Here, we aim at building statistical models to establish the ecological niches of 11 aquatic macrophytes (10 different phanerogams and the genus Nitella) from oligotrophic soft-water lakes and infer their ecological requirements and environmental constraints at the southernmost limit of their distribution. Macrophyte occurrence and environmental variables were obtained from 86 non-exploited oligotrophic soft-water lakes from the Pyrenees (Southern Europe; $\left.42^{\circ} 50^{\prime} \mathrm{N}, 1^{\circ} 00^{\prime} \mathrm{E}\right)$; macrophytes inhabited 55 of these lakes. Optimum ranges and macrophyte occurrence were predicted in relation to 18 geographical, morphological, catchment and water chemistry variables using univariate and multivariate logistic models. Lakes at low altitude, in vegetated catchments and with low water concentration of $\mathrm{NO}_{3}{ }^{-}$and $\mathrm{SO}_{4}^{-2}$, were the most suitable to host macrophytes. In general, individual species of aquatic macrophytes showed clear patterns of segregation along conductivity and pH gradients, although the specific combination of variables selected in the best models explaining their occurrence differed among species. Based on the species response to $\mathrm{pH}$ and conductivity, we found Isoetes lacustris have its optimum in waters with low conductivity and pH (i.e., negative monotonic response). In contrast, Callitriche palustris, Ranunculus aquatilis, Subularia aquatica, Nitella spp., and Myriophyllum alterniflorum showed an optimum at intermediate values (i.e. unimodal response), whereas Potamogeton berchtoldii, Potamogeton alpinus, and Ranunculus trichophyllus as species had their optimum at relatively high water pH and conductivity (1.e. positive monotonic response). This pattern has been observed in other regions for the same species, although with different optima and tolerance ranges. The parsimonious models developed here allowed us to explore niche requirements for each species and to predict the occurrence of macrophytes and of individual species in any particular lake by using only few, easily measured environmental variables. This is of interest to forecast possible changes related to global change and to assist managers in making conservation, management and restoration decisions.
\end{abstract}

Key words: Aquatic plants, presencelabsence, prediction, optimum range, ecological niche, logistic models.

Received: February 2014. Accepted: July 2014.

\section{INTRODUCTION}

Lowland lakes are well known to suffer directly from local and regional human impacts such as acidification, eutrophication, alkalinisation, water exploitation, or species introductions (Arts, 2002; Murphy, 2002; Chappuis et al., 2011b). Mountain lakes, in contrast, tend to be more exposed to global environmental pressures such as acidification (Camarero et al., 1995), increased atmospheric nitrogen deposition rates (Catalan et al., 1994; Mosello et al., 2002), or global warming (Schindler et al., 1996; Sommaruga-Wograth et al., 1997), and they may be also directly impacted by hydrologic exploitation (Catalan et al., 1997). Lake macrophyte assemblages can respond variously depending on the severity of these impacts. While small impacts may cause only minor shifts in species abundances, moderate impacts may modify the structure of species assemblages, and severe impacts may lead to the disappearance of some species if the new conditions fail to supply their ecological requirements (Egertson et al., 2004).

The rich and fragile macrophyte flora from oligotrophic lakes and ponds (Chappuis et al., 2014) has largely suffered from man-induced acidification, eutrophication (Arts, 2002), damming (Gacia and Ballesteros, 1996) and is now facing the threats related to climate change (Mooij et al., 2005). Within the last decades, significant efforts have been done in Central and Northern Europe to restore and recover some of these endangered systems and species, affected by local eutrophication, through reductions in the organic load in lake sediments (Brouwer and Roelofs, 2001).

The Pyrenean mountain range (Southern Europe; $42^{\circ} 50^{\prime} \mathrm{N}, 1^{\circ} 00^{\prime} \mathrm{E}$ ) holds several thousand oligotrophic soft-water lakes, mainly distributed between 1600 and $2500 \mathrm{~m}$ asl, of which approximately $65 \%$ host aquatic macrophytes (Gacia et al., 1994). As a redoubt of the quaternary glaciation flora, Pyrenean lakes provide habitat 
to species that are widely distributed in Central and Northern Europe (Murphy, 2002) and provide a refuge to species that are considered threatened or vulnerable to extinction in the Iberian Peninsula (e.g., Callitriche palustris L., Potamogeton alpinus Balb, and P. perfoliatus L., P. praelongus Wulfen; Bañares et al., 2010). Thus, Pyrenean lakes hold a wide subset of the European aquatic macrophytic flora in a relatively restricted area (i.e., small latitude and longitude ranges), which makes them extremely valuable for an accurate assessment of the ecological requirements of each of these species.

Knowledge on the occurrence and distribution of aquatic macrophytes in the Pyrenees is rather limited. Gacia et al. (1994) presented the most comprehensive list of species distribution, together with a heuristic multivariate analysis of their relations with environmental variables. Here we build on their research by developing predictive statistical models to establish the ecological niches of individual aquatic macrophytes in these lakes, and to infer their ecological requirements and environmental constraints. The goal of Gacia et al. (1994) was to explore and describe the relationships between environmental variables and the occurrence of macrophytes in Pyrenean lakes. Consequently, they used multivariate techniques (in particular, redundancy analysis) that showed the most parsimonious set of environmental variables that could explain species occurrence, together with the similarities among species in their response to those variables. Those models were, however, not directed at prediction, and therefore have limited use as management tools. In the present paper, we aim to develop predictive models that produce best estimates of the probability of occurrence for individual species with prediction error, that are parsimonious, that include easy-to-measure variables, and that contain the best set of predictors for each individual species. It is reassuring that the main explanatory variables in the multivariate analysis are consistent with the main predictors selected in logistic models developed here.

To achieve our goals, we looked at the distribution of aquatic macrophytes as a function of a set of geographical, morphological, catchment, and water chemistry variables, and build univariate and multivariate, monotonic and unimodal logistic models based on presence/true absence data. Logistic models can help to better understand species occurrence and responses to environmental factors (van den Berg et al., 2003; van Nes et al., 2003; Abeli et al., 2012) and are able to predict the probability of occurrence of a species as a function of a single or multiple environmental variables. This approach allows us to both define the autoecology of the species and to predict their occurrence in a lake, which is a valuable tool to assist in the conservation and the restoration of the assemblages of aquatic macrophytes, especially in those systems with incomplete records of former macrophyte populations or that may require of species introduction due to isolation or lack of recruitment.

\section{METHODS}

\section{Database}

Macrophyte occurrence and environmental variables were obtained by merging two datasets (Catalan et al., 1993; Gacia et al., 1994) resulting in data for 86 nonexploited Pyrenean oligotrophic soft-water lakes, with aquatic macrophytes occurring in fifty-five of these lakes (Fig. 1).

Logistic regression models were developed to predict the occurrence of the most common aquatic macrophytes in the sampling area. The most common species, i.e. those present in more than $10 \%$ of the sampled lakes with macrophytes, were in order of abundance: Sparganium angustifolium Michx $(\mathrm{n}=40)$, Isoetes lacustris $\mathrm{L} .(\mathrm{n}=25)$, Subularia aquatica $\mathrm{L}$. $(\mathrm{n}=22)$, P. berchtoldii Fieber $(\mathrm{n}=22)$, Nitella spp. $(\mathrm{n}=22)$, I. echinospora Durieu $(\mathrm{n}=19$, I. setacea in Gacia et al., 1994), Ranunculus aquatilis $\mathrm{L}$. ( $\mathrm{n}=15), P$. alpinus $(\mathrm{n}=14), C$. palustris $(\mathrm{n}=9)$, Myriophyllum alterniflorum DC. $(\mathrm{n}=8)$, and R. trichophyllus Chaix. $(\mathrm{n}=7)$.

Macrophyte occurrence was predicted in relation to 18 environmental variables classified as geographical, morphometric, catchment vegetation and water chemistry variables (Tab. 1). Environmental variables were obtained as explained in Gacia et al. (1994) from a single sampling day synchronic to plant collection. Data were collected during midsummer (i.e., the peak growing season of macrophyte species), which shows minor variation across time for each system (Camarero et al., 2009). The only additional environmental variable introduced in the current analysis was littoral mean slope. The mean slope of a $60 \mathrm{~m}$ sector created outside the lake shore was included in the analysis as a proxy of the mean slope of the littoral of the lake. Mean slope was calculated from a $15 \mathrm{~m} \times 15 \mathrm{~m}$ cell size digital elevation model (DEM) obtained from Institut Cartogràfic de Catalunya (ICC) using the software ESRI ArcMap 10.0. Missing maximum depth lake values $(40 \%)$ were replaced by predicted values using a regression between measured lake depth data and lake area $\left(\mathrm{R}^{2}=0.45, \mathrm{P}<0.001\right)$ to maximize the number of lakes used in the analysis:

Lake depth $=0.438 \log ($ Lake area $)+1.431$

(eq. 1)

The dominant vegetation community of the catchment was categorized as an ordered factor based on the main vegetation of the catchment as follows: 1, without vegetation; 2, Festuca eskia; 3, mixed meadows of Festuca spp. with shrubs of Rhododendron ferrugineum; 4, Carex curvula; 5, R. ferrugineum, and 6, Pinus uncinata. All 
$N$

FRANCE

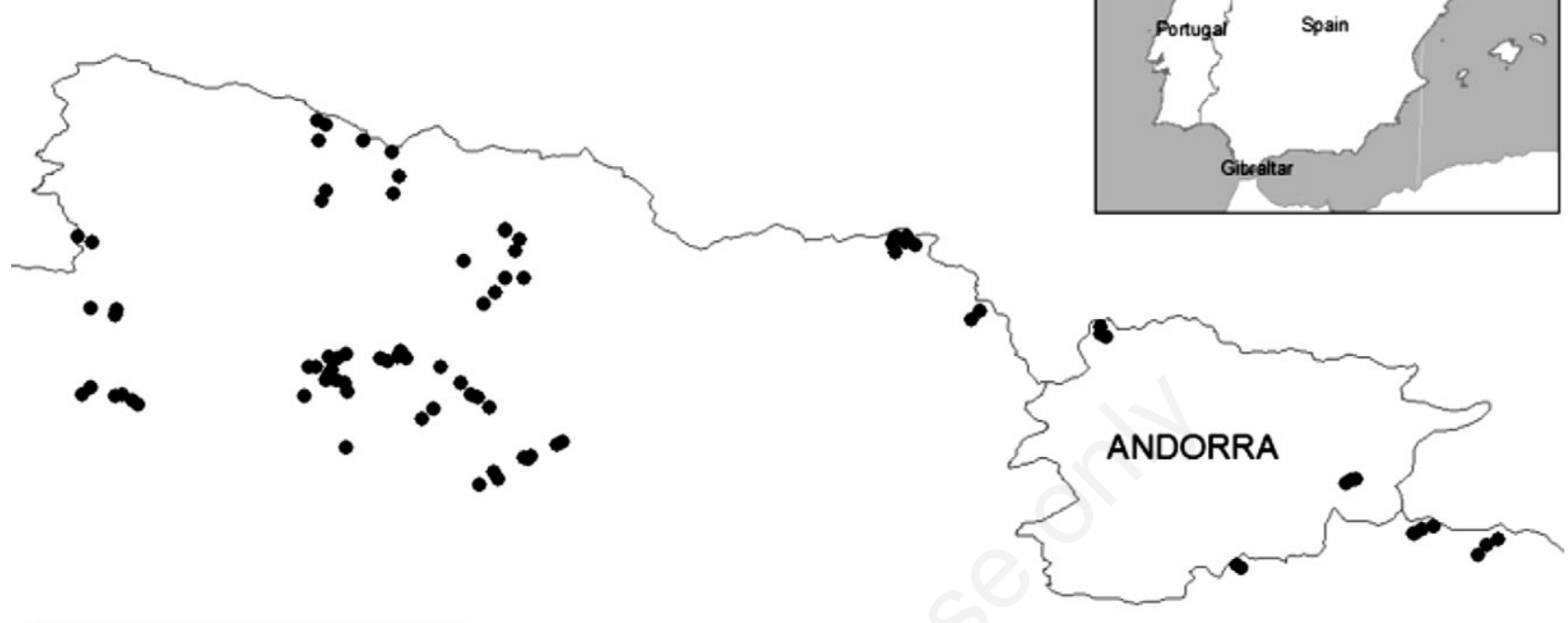

- Sampled lakes

\section{$0 \quad 5 \quad 10 \quad 20 \mathrm{Km}$}

\section{SPAIN}

Fig. 1. Location of the lakes under study.

Tab. 1. Explanatory variables used in the models, with mean, minimum and maximum values by category.

\begin{tabular}{|c|c|c|c|c|c|c|c|c|}
\hline \multirow[t]{2}{*}{ Category } & \multirow{2}{*}{$\begin{array}{c}\text { Environmental } \\
\text { variable }\end{array}$} & \multirow[t]{2}{*}{ Unit } & \multicolumn{3}{|c|}{ All lakes } & \multicolumn{3}{|c|}{ Only lakes with macrophyte } \\
\hline & & & Mean & Min & Max & Mean & Min & Max \\
\hline Geographical & Altitude & $\mathrm{m}$ & 2246 & 1620 & 2581 & 2201 & 1620 & 2520 \\
\hline \multirow[t]{4}{*}{ Morphometric } & Catchment area & ha & 287 & 3 & 4894 & 336 & 3 & 4894 \\
\hline & Lake area & ha & 4.0 & 0.2 & 46 & 3.7 & 0.2 & 29.4 \\
\hline & Maximum depth & $\mathrm{m}$ & 8 & 1 & 32 & 9 & 1 & 32 \\
\hline & Mean slope & $\%$ & 14 & 6 & 23 & 14 & 6 & 22 \\
\hline \multirow[t]{2}{*}{ Catchment vegetation } & Vegetation $^{\circ}$ & & 4 & 2 & 6 & 4 & 2 & 6 \\
\hline & Peat bog & $\%$ & 24 & 0 & 100 & 24 & 0 & 100 \\
\hline \multirow[t]{11}{*}{ Water chemistry } & Alkalinity & $\mu \mathrm{EqL}^{-1}$ & 169 & -162 & 650 & 175 & 7 & 650 \\
\hline & Conductivity & $\mu \mathrm{Scm}^{-1}$ & 23 & 4 & 78 & 23 & 4 & 78 \\
\hline & $\mathrm{pH}$ & & 6.9 & 4.5 & 7.7 & 6.9 & 5.7 & 7.7 \\
\hline & TP & $\mu \mathrm{M}$ & 0.4 & 0.1 & 8.3 & 0.4 & 0.1 & 8.3 \\
\hline & $\mathrm{NH}_{4}^{+}$ & $\mu \mathrm{M}$ & 1.7 & bd & 10.0 & 1.7 & bd & 10.0 \\
\hline & $\mathrm{NO}_{3}^{-}$ & $\mu \mathrm{M}$ & 9.5 & bd & 39.2 & 7.4 & bd & 21.6 \\
\hline & $\mathrm{Cl}^{-}$ & $\mu \mathrm{M}$ & 13 & 1 & 82 & 12 & 1 & 66 \\
\hline & $\mathrm{SO}_{4}^{2-}$ & $\mu \mathrm{M}$ & 21 & 4 & 118 & 18 & 4 & 39 \\
\hline & $\mathrm{Na}^{+}$ & $\mu \mathrm{M}$ & 26 & 9 & 87 & 27 & 10 & 87 \\
\hline & $\mathrm{K}^{+}$ & $\mu \mathrm{M}$ & 8 & 1 & 100 & 7 & 1 & 43 \\
\hline & $\mathrm{Mg}^{2+}$ & $\mu \mathrm{M}$ & 8 & 2 & 33 & 8 & 2 & 33 \\
\hline
\end{tabular}

${ }^{\circ}$ Dominant catchment vegetation: 1 , without vegetation; 2, Festuca eskia; 3, mixed meadows of Festuca spp. with shrubs of Rhododendron ferrugineum, 4, Carex curvula; 5, R. ferrugineum; 6, Pinus uncinata; bd, below detection limit. 
environmental variables were $\log$ transformed before analysis except for altitude, vegetation, peat bog, and $\mathrm{pH}$. The environmental variables were tested for independence using Pearson correlation coefficients. Most correlation coefficients between variables were smaller than 0.5 . Since alkalinity was highly correlated to $\mathrm{Ca}^{2+}(\mathrm{r}=0.95), \mathrm{Ca}^{2+}$ was not used to develop the models (Supplementary Tab. 1).

\section{Logistic regression models and data analysis}

Logistic regression models were developed first to predict the probability of occurrence of any aquatic macrophyte using the whole set of water bodies $(n=86)$, and then to predict the occurrence of individual macrophyte species using only those water bodies where macrophytes of any species occurred $(n=55)$. Exceptionally, the whole set of water bodies were used to predict the occurrence of $S$. angustifolium and $I$. echinospora in order to improve the explained deviance by the logistic models. We chose to fit logistic models to our species distribution data because they are a tried and tested statistical technique that produces predictive models and takes full advantage of presence and true absence data.

The probability of occurrence of a species $P(\mathrm{x})$ as a function of an explanatory variable $\mathrm{x}$ was fitted using logistic regression according to the following equation:

$P(x)=\frac{e^{\beta_{0}+\beta_{1} x+\beta_{2} x^{2}}}{1+e^{\beta_{0}+\beta_{1} x+\beta_{2} x^{2}}}$

where $\beta_{0}, \beta_{1}$ and $\beta_{2}$ are regression coefficients estimated by maximum likelihood. When the quadratic term $\left(\beta_{2}\right)$ is set to zero, the model reduces to a sigmoidal increase or decrease in the probability of occurrence, and the probability of occurrence follows a monotonic distribution. When $\beta_{2}$ differs from 0 the resulting response curve is symmetrical and bell-shaped, and the probability of occurrence follows a unimodal distribution. We fitted Eq. 2 within the framework of general linear models with the usual link function (logit) and binomial errors using function $\mathrm{glm}$ in the statistics package of $\mathrm{R}$ ( $\mathrm{R}$ Core Development Team, 2012).

Eq. 2 can be easily extended to include more than one explanatory variable (multiple regression models). Logistic models using only one variable (univariate) were used to select the variables that significantly explained macrophytes distribution (chi-square test $\mathrm{P} \leq 0.05$ ) and to estimate optimum ranges following Peeters et al. (1998) approach, where optimum range is defined as the range of the environmental variable for which the probability of occurrence divided by the maximum probability of occurrence $(P \max )$ is 0.75 or higher (see Supplementary Tab. 2 for $P \max$ values and ranges obtained from the estimates of the parameters $\beta_{1}$, and $\beta_{2}$ ). Only variables that were significant in univariate models were considered as candidate predictors in multiple regression models. When a variable was significant in both monotonic and unimodal models, then the model with the lowest corrected Akaike information criterion (AICc, corrected for small sample size) was used.

Selection of multiple regression models was done with exhaustive search for the best model among candidate models, based on AICc values, by using function glmulti (in R glmulti package). Because the number of observations and, especially, the number of presences was generally low, we limited target models to a maximum of four predictor terms and did not consider interactions. We defined a confidence set of models for each dependent variable that consisted in all those models that differed $\leq 2 \mathrm{AICc}$ units from the model with the lowest AICc value. Models within a confidence set are essentially undistinguishable in terms of their fit to the data. Model goodness-of-fit was measured by the adjusted proportion of explained deviance $\left(\mathrm{D}^{2}{ }_{\text {adj }}\right)$ following Liu et al. (2011). This statistic is a general linear model analogue of ordinary regression $\mathrm{R}^{2}$ and ranges from 0 (no fit) to 1 (perfect fit). Additionally, the best model in each confidence set was validated using leave-one-out cross validation with a threshold of 0.5 (i.e., predicted probability greater that 0.5 is interpreted as presence, otherwise as absence) to compare predicted occurrence with observed presence or absence. Leave-one-out cross validation involves using a single observation from the original sample as the validation data, and the remaining observations as the training data. This is repeated such that each observation in the sample is used once as the validation data.

The weight of evidence for a model within the confidence set was measured using Akaike weights (Wagenmakers et al., 2004). A high Akaike weight for the best model (for example, greater than 0.8 ) would mean that this model was substantially better that the other models. Akaike weights for model sets add up to 1 . The importance of predictor terms can be evaluated by summing up the Akaike weights of all models were a term appears. Thus, a predictor variable that appears in all the models in the confidence set would have a value of importance of 1. All statistical analyses and graphs were done with the R language (R Core Development, 2012).

\section{RESULTS}

The Pyrenean lakes considered in the data base are distributed across an altitude range of almost $1000 \mathrm{~m}$, including both sub-alpine and alpine lakes (Tab. 1). The sampled lakes were mainly oligotrophic $\left(\mathrm{NO}_{3}{ }^{-}<40 \mu \mathrm{M}\right.$, $\mathrm{NH}_{4}{ }^{+}<10 \mu \mathrm{M}$ and $\mathrm{TP}<10 \mu \mathrm{M}$ ) and soft-water (alkalinity $<1000 \mu \mathrm{M}$; Tab. 1). 


\section{Presence of any macrophytes}

Altitude, dominant vegetation in the catchment, $\mathrm{NO}_{3}$ and $\mathrm{SO}_{4}{ }^{2-}$ were the significant variables predicting the occurrence of macrophytes in univariate models (Tab. 2). Probability of macrophyte presence decreased with altitude and $\mathrm{SO}_{4}{ }^{2-}$ concentrations in water, and increased with the categorical variable dominant vegetation following a monotonic distribution (Tab. 2; Fig.2). In contrast, macrophyte presence followed a unimodal relationship with the $\log$ of $\mathrm{NO}_{3}{ }^{-}$concentration (Tab. 2; Fig. 2) but in practical terms, the probability of macrophyte presence decreased with increasing nitrate concentrations. Therefore, macrophytes were more likely to be present in lakes at low altitudes (between 1620 and $2188 \mathrm{~m}$ asl), in well forested catchments, and low water concentrations of $\mathrm{NO}_{3}^{-}$(below $8.3 \mu \mathrm{M}$ ) and $\mathrm{SO}_{4}{ }^{2-}$ (between 4 and $15 \mu \mathrm{M}$; Tab. 2; Supplementary Tab. 2). The best multiple regression model included all four variables and explained more than $30 \%$ of the deviance, with a cross validation error of 0.21 (Tab. 3). All the variables had the same importance (1.00; Tab. 4) because this was the only model in the confidence set (Supplementary Tab. 3).

\section{Presence of individual species}

When univariate models were used to predict the occurrence of individual species, $\mathrm{pH}$ and conductivity were the variables that significantly explained the occurrence of the highest number of species ( $\mathrm{n}=9$ species; Tab. 2), followed by catchment vegetation and alkalinity $(\mathrm{n}=8$ species; Tab. 2$)$, and $\mathrm{K}^{+}$concentration $(\mathrm{n}=6$ species; Tab. 2). On the other hand, the concentration of TP and $\mathrm{NH}_{4}{ }^{+}$were the variables that significantly explained the occurrence of the lowest $(n=1)$ number of species (Tab. 2). Based on the species response to $\mathrm{pH}$ and conductivity (Fig. 3; Supplementary Tab. 2), we found that I. lacustris had its optimum in waters with low conductivity (4-11 $\mu \mathrm{Scm}^{-1}$ ) and $\mathrm{pH}$ (5.7-6.4; i.e., negative monotonic response). In contrast, C. palustris (12-24 $\left.\mu \mathrm{S} \mathrm{cm}^{-1} ; 6.2-6.8\right)$, R. aquatilis (16-35 $\left.\mu \mathrm{S} \mathrm{cm}^{-1} ; 6.6-7.1\right), S$. aquatica (12-40 $\mu \mathrm{S} \mathrm{cm}^{-1}$; 6.7-7.4), Nitella spp. (16-57 $\left.\mu \mathrm{Scm}^{-1} ; 5.7-6.4\right)$, and M. alterniflorum $\left(21-35 \mu \mathrm{S} \mathrm{cm}^{-1} ; 7.0-7.3\right)$, with an optimum at intermediate values (i.e., unimodal response). Finally, $P$. berchtoldii (36-78 $\left.\mu \mathrm{S} \mathrm{cm}^{-1} ; 7.3-7.7\right)$, P. alpinus $(47-78 \mu \mathrm{S}$ $\left.\mathrm{cm}^{-1} ; 7.3-7.7\right)$, and $R$. trichophyllus $\left(58-78 \mu \mathrm{S} \mathrm{cm}^{-1} ; 7.5\right.$ 7.7), had their optima at relatively high water $\mathrm{pH}$ and conductivity (i.e., positive monotonic response). A similar pattern in the species distribution was found in relation to water alkalinity, although this variable explained the occurrence of fewer species (Tab. 2; Supplementary Tab. 2). When looking at the species response to catchment vegetation, P. alpinus and $R$. trichophyllus were more likely to be found in catchments where the dominant vegetation were herbaceous plants (i.e. Festuca spp. or C. curvula),

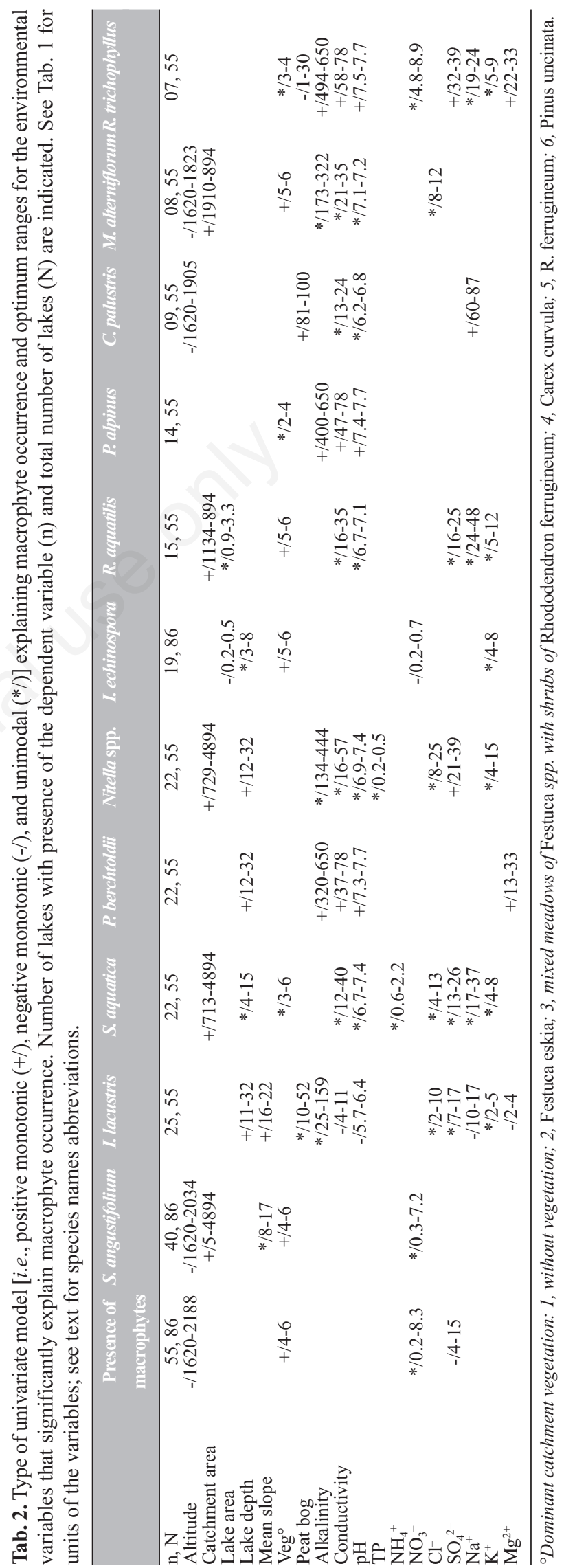


whereas I. echinospora, M. alterniflorum and R. aquatilis tended to occur in catchments where the dominant vegetation were shrubs or trees, and $S$. aquatica and $S$. angustifollium in catchments with herbaceous vegetation, shrubs or trees (Tab. 2; Supplementary Tab. 2). TP significantly explained the probability of occurrence of the three isoetids, the two Ranunculus species and the Nitella genus (Tab. 2; Supplementary Tab. 2). The relationship between macrophyte occurrence and $\mathrm{K}^{+}$followed a unimodal distribution and the optimum ranges went from 2 to $15 \mu \mathrm{M}$ (Tab. 2; Supplementary Tab. 2).

The combination of variables selected for the best models explaining individual species occurrence differed among species (Tab. 3). For instance, the occurrence of $P$. alpinus was modeled using only water chemistry variables, while the best model for I. echinospora included also morphometric and catchment vegetation variables. The goodness-of-fit $\left(\mathrm{D}_{\text {adj }}^{2}\right)$ and the validation of the model also varied depending on the species (Tab. 3). The model with the highest goodness-of-fit $\left(\mathrm{D}_{\text {adi }}^{2}=79\right)$ and one of the lowest cross validation $(\mathrm{C}-\mathrm{V})$ values $(0.109$; Tab. 3$)$ was the best of models predicting $R$. trichophyllus occurrence. The best models for $R$. aquatilis, M. alterniflorum, C. palustris, $P$. alpinus and $P$. berchtoldii had higher $\mathrm{D}^{2}$ adj and lower $\mathrm{C}-\mathrm{V}$ values than the best model for macrophyte occurrence $\left(\mathrm{D}_{\text {adj }}^{2}=0.304 ; \mathrm{C}-\mathrm{V}=0.201 ;\right.$ Tab. 3). By contrast, even the best models for Nitella spp., S. aquatica, I. lacustris, I. echinospora, and $S$. angustifolium had lower goodness-offit and higher cross-validation error that the best model for macrophyte occurrence (Tab. 3).
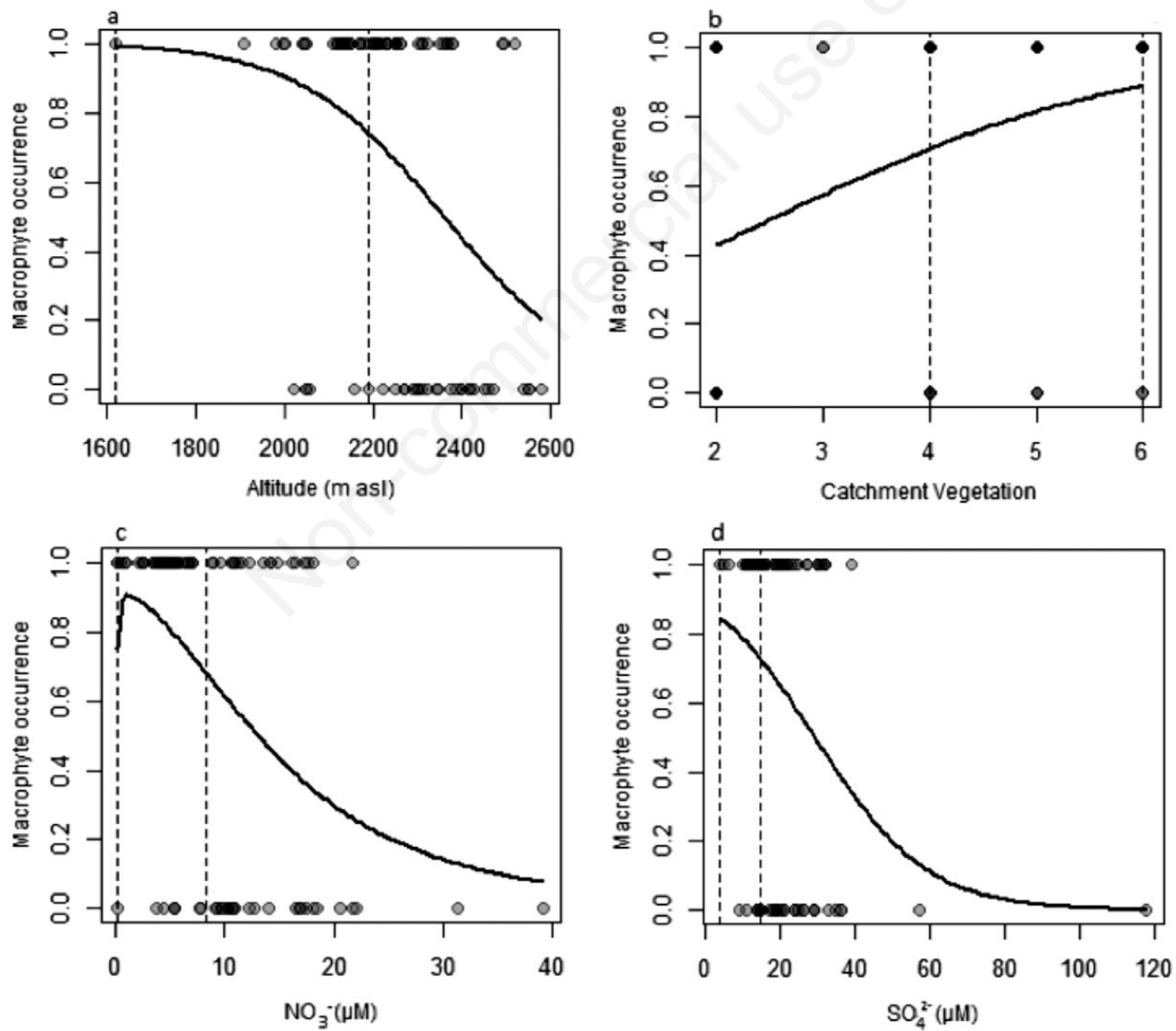

Fig. 2. Macrophyte occurrence in relation to altitude (a), dominant catchment vegetation (b) (1, without vegetation; 2, Festuca eskia; 3, mixed meadows of Festuca spp. with shrubs of Rhododendron ferrugineum; 4, Carex curvula; 5, Rhododendron ferrugineum; 6, Pinus uncinata), water $\mathrm{NO}_{3}^{-}$(c) and $\mathrm{SO}_{4}{ }^{2-}(\mathrm{d})$. Optimum ranges are indicated by dashed lines. 
The confidence sets (set of models with $\Delta \mathrm{AICc} \leq 2$ ) for $P$. berchtoldii and $R$. aquatilis included a single model (Supplementary Tab. 3). For all other species, several models competed with the best model (Tab. 3; Supplementary Tab. 3). Water $\mathrm{pH}$, dominant catchment vegetation, conductivity, altitude and $\mathrm{K}^{+}$concentration were the most important environmental variables in the confidence sets of models (Tab. 4), consistently with the best set of predictor in univariate models. Considering the predictor terms of all models in the confidence sets (Tab. 4), water chemistry variables were always select the occurrence of species. In addition to water chemistry variables, the three isoetid species required also morphometric and catchment vegetation variables.

\section{DISCUSSION}

\section{Environmental conditions and presence of aquatic macrophytes}

High mountain lakes can offer conditions that are too harsh for the development of macrophytic vegetation. Thus, out of 86 natural lakes surveyed, only 55 had macrophytic vegetation. In our models, the presence of macrophytes was significantly explained by altitude, dominant vegetation in the catchment, and concentrations of $\mathrm{SO}_{4}{ }^{2-}$ and $\mathrm{NO}_{3}{ }^{-}$in the water column. Therefore, Pyrenean lakes situated at low altitudes, in vegetated catchments and with low $\mathrm{NO}_{3}{ }^{-}$and $\mathrm{SO}_{4}{ }^{2-}$ concentrations are more likely to host aquatic macrophytes.

Altitude is a strong factor determining the presence and diversity of aquatic macrophytes because it is directly linked to proximate environmental constraints such as icecover duration, average temperature or light availability (Gacia et al., 1994; Murphy, 2002; Lacoul and Freedman, 2006; Chappuis et al., 2011a). Regional studies from alpine lakes in Europe have shown that ice-cover duration determines the presence and succession of some phytoplankton and zooplankton species and communities, and therefore dominates the dynamics of the lake ecosystem (Catalan et al., 2009). Similarly, ice-cover duration also determines the length of the growing season for macrophytes (Lacoul and Freedman, 2006), since it regulates the entrance of energy (light and temperature) and availability of nutrients (through stratification), which are factors that directly affect the life cycle of macrophytes (Barko and Smart, 1981; Gacia and Ballesteros, 1994). Above a certain altitude, the duration of the ice-cover is so long that the open-water period required by plants to develop is too short (Lacoul and Freedman, 2006). Thus, there seems to be an upper limit to the altitude at which macrophytes can be found, which in our dataset is recorded at $2520 \mathrm{~m}$ asl in Estany Engorgs, where $R$. aquatilis was present. However, there is no evidence of a clear cut altitude threshold for the presence

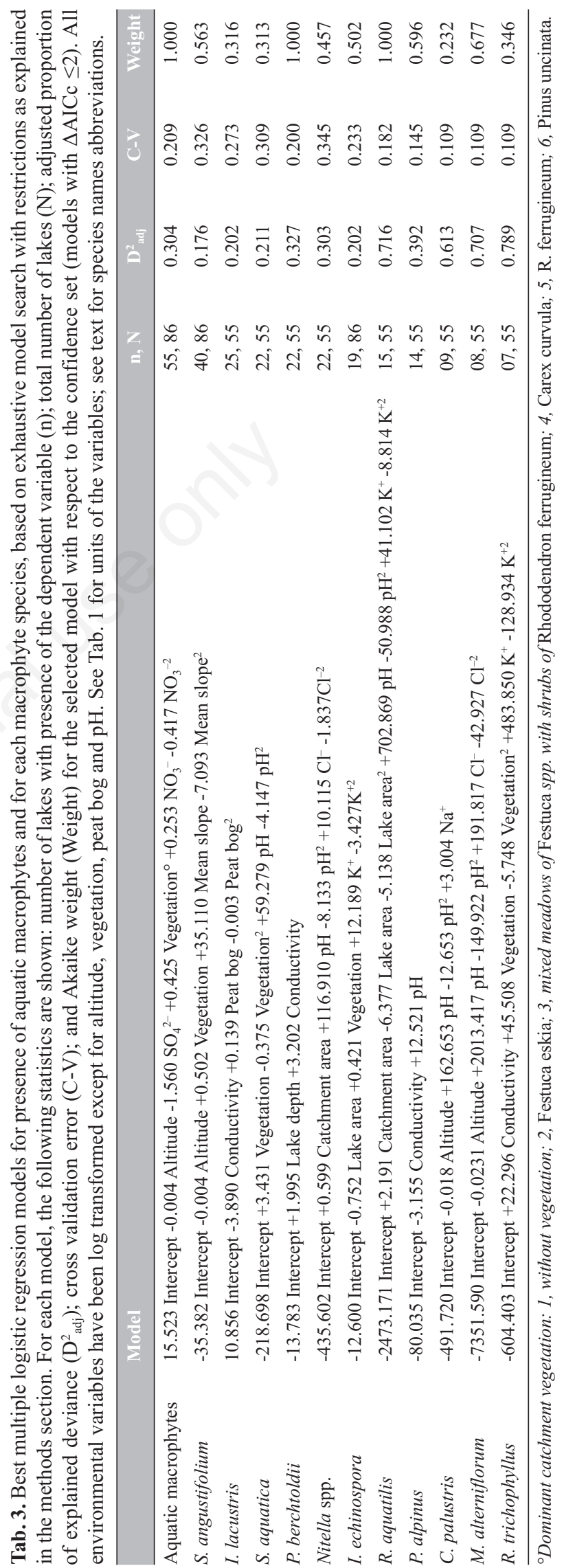


of macrophytes; if altitude imposes a limit, it must vary with each species and with the characteristics of lakes, including lake morphometry and landscape position (orientation, fetch, exposure, etc.).

Dominant catchment vegetation was also an important variable for predicting the occurrence of macrophytes. The probability of occurrence increased from herbaceous plants to shrubs and to forest communities, with the exception of $R$. trichopyllus and P. alpinus, which found their optimum ranges in lakes with catchments dominated by herbaceous plants. Dominant catchment vegetation integrates information about weather, altitude, geology and land use. For instance, in the Pyrenees, forests of $P$. uncinata are found up to $2300-2450 \mathrm{~m}$ asl, with mean temperatures averaging $10-12^{\circ} \mathrm{C}$ over the growing season (Ninot et al., 2008). Above the tree line, weather conditions are so extreme (low temperatures, high wind, and long snow cover periods) that only shrubs and herbs are able to grow. Similarly, Festuca gautieri is indicative of calcareous soils and Festuca eskia is more common in siliceous soils, but both are major constitutive elements of subalpine to alpine pastures (Segarra-Moragues and Catalan, 2011). Moreover, catchment vegetation also buffers the entrance of nutrients into the lakes, taking up $\mathrm{N}$ and $\mathrm{P}$, and reducing erosion and surface runoff (Lee $e t$ al., 2003). The optimum $\mathrm{NO}_{3}{ }^{-}$range for occurrence of any macrophytes species fell at low concentrations (below 8.3 $\mu \mathrm{M})$. The concentration of $\mathrm{NO}_{3}{ }^{-}$in the waters of these lakes depends on inputs through atmospheric deposition (which is low in the Pyrenees compared to the rest of Europe; Camarero and Catalan, 1993), on the buffer capacity of the catchment vegetation (Lee et al., 2003; Camarero et al., 2009), and on the uptake of $\mathrm{NO}_{3}{ }^{-}$by the macrophytes inhabiting the lake (Gacia and Ballesteros, 1994; Olsen and Andersen, 1994). Macrophyte presence, S. angustifolium and $R$. trichophyllus followed a unimodal relationship with $\mathrm{NO}_{3}^{-}$, whereas the isoetid I. echinospora followed a negative monotonic relationship with optimum $\mathrm{NO}_{3}{ }^{-}$concentrations at $0.7 \mu \mathrm{M}$. Isoetes echinospora inhabits small ( 0.2 to $0.5 \mathrm{ha}$ ), shallow ( 3 to $8 \mathrm{~m}$ ) lakes that are highly affected by plant activity because of the low volume to surface water ratio. Isoetes species can promote low $\mathrm{N}$ concentration in those lakes (Gacia et al., 2009) taking up $\mathrm{NO}_{3}{ }^{-}$as $\mathrm{N}$ source (Schuurkes et al., 1986) and enhancing net $\mathrm{N}$ losses, as isoetids promote coupling of nitrification and denitrification through high root oxygen losses (Risgaard-Petersen and Jensen, 1997).

The probability of occurrence of macrophytes followed a negative monotonic relationship with $\mathrm{SO}_{4}{ }^{2-}$, with an optimum at the lower range of observed concentrations, from 4 to $15 \mu \mathrm{M}$. Sulphate can enter the system by atmospheric deposition (Camarero and Catalan, 1993), but most chemical variance in the studied area is related to bedrock weathering (Catalan et al., 1993).

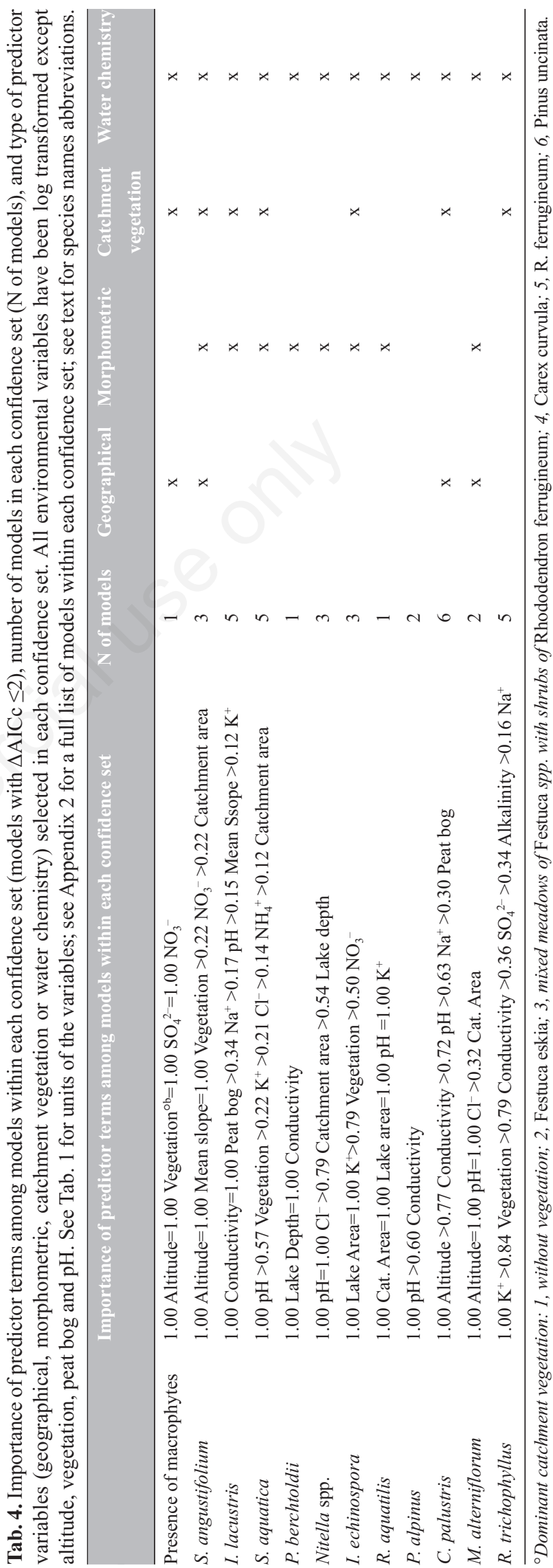


Sulphate can lead to sulphide toxicity in lakes with high oxygen demand in their sediments (Pulido et al., 2012a) and can also acidify the system, compromising soft-water vegetation (Arts, 2002). Thus, high concentrations of sulphate appear to prevent the development of macrophytes, yet within the range found in lakes with aquatic vegetation, sulphate does not seem to impose any constraints, as this variable is never a significant predictor of the presence of individual species.

\section{Distribution of individual species}

The probability of occurrence of every species has been explained by different combinations of environmental variables and different relationships, suggesting the existence of individual responses and optimal ranges. However, water conductivity and $\mathrm{pH}$ were the most relevant variables predicting the occurrence of most species in these extreme soft-water systems. Water conductivity is a proxy for water alkalinity (Gacia et al., 1994) and, together with $\mathrm{pH}$, determines carbon availability. Indeed, carbon metabolism arises as the main driving factor determining species distribution in softwater lakes. The isoetid I. lacustris grows at the lowest conductivity and $\mathrm{pH}$ values, and occurs within a very narrow range of water conductivity, featuring a specialized and very vulnerable species (Pip, 1988). I. lacustris behaves similarly throughout its biogeographical distribution range (Toivonen and Huttunen, 1995; Heegaard et al., 2001; Pulido et al., 2012b) and holds particular structural and physiological adaptations to ensure an efficient use of $\mathrm{CO}_{2}$ for the photosynthesis (Rascio, 2002). At the upper limit of the conductivity range within the Pyrenean context, we encounter two Potamogeton species ( $P$. alpinus and P. berchtoldii) and $R$. trichophyllus, which, as expected, also show a broader tolerance range. The photosynthesis of these aquatic macrophytes relies on $\mathrm{HCO}_{3}{ }^{-}$use, which is an adaptation that becomes relevant at relatively high carbon availability and pH (Madsen and Sand-Jensen, 1991). In between the extreme values of water conductivity, we encounter a number of species (Callitriche palustris, $R$. aquatilis, $S$. aquatica and $M$. alterniflorum) with no overlapping ranges; an exception is the alga Nitella (probably encompassing different species in our surveys), which is distributed over a broad range of conductivity.

The distribution range for the species adapted to low water conductivity and $\mathrm{pH}$ does not overlap with those encountered at intermediate ranges, which in turn slightly overlap with the ones adapted to high conductivities. These two apparent discontinuities may be the consequence of inter-specific interactions that modulate ecological optima and tolerance ranges in such a way that inter-specific competition is reduced (Pip, 1984, 1988). Within each range group, species with similar conductivity tolerance range have slightly different optimums, also suggesting niche segregation and optimum exclusion to minimize competition. There are also some species with similar conductivity tolerance and optimum (i.e., C. palustris, $R$. aquatilis, S. aquatica, M. alterniflorum) but they use
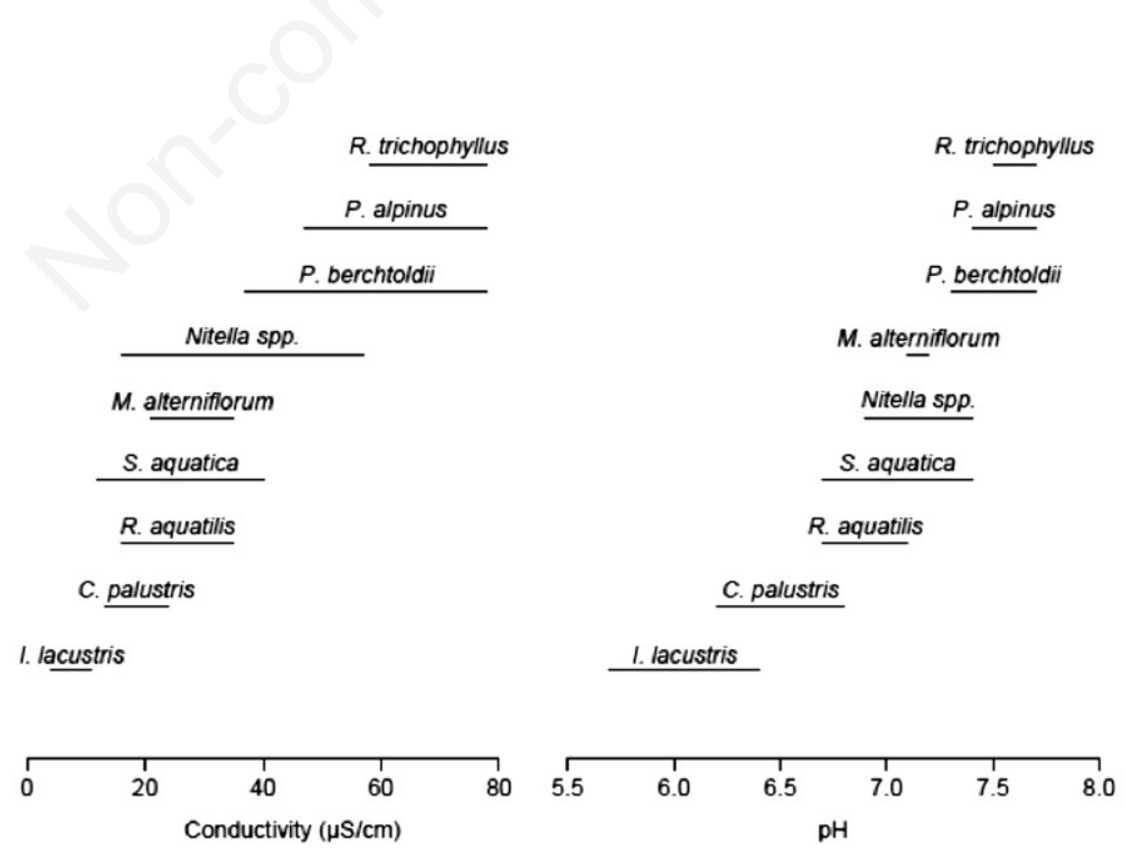

Fig. 3. Conductivity and $\mathrm{pH}$ optimum ranges for the species whose occurrence are significantly explained by those variables. The optimum range is defined as the range of the environmental variable for which the probability of occurrence divided by the maximum probability of occurrence $(P \max )$ is 0.75 or higher. 
different growth strategies (isoetids $v s$. natopotamids) or occupy different zones inside the lake (Gacia et al., 2009).

The distribution of macrophytes in relation to conductivity and $\mathrm{pH}$ was very similar. However, while there was a gradual response for $\mathrm{pH}$, conductivity showed irregular patterns. The highly abundant species $M$. alterniflorum can be found at lakes with intermediate conductivity but shows a surprisingly narrow range for $\mathrm{pH}$ which should be the subject of further studies. The potential of the species to modify water column $\mathrm{pH}$ cannot be discarded given its high primary production at the time the samples were gathered.

The results of logistic regressions were compared with data from the literature. Although several studies have focused on determining the environmental variables affecting soft-water macrophytes (Seddon, 1972; Toivonen and Huttunen, 1995; Pulido et al. 2012b), only a handful of studies (Pip, 1988; Heegaard et al., 2001) reported optimum ranges for a relevant number of species found in this study (I. lacustris, S. angustifolium, M. alterniflorum, P. berchtoldii, P. alpinus). Nonetheless, optimum ranges for parameters such as $\mathrm{pH}$ and conductivity can also be inferred from other studies, including Seddon (1972) and Toivonen and Huttunen (1995). All studies placed I. lacustris at the low $\mathrm{pH}$ and conductivity range, $S$. aquatica, $M$. alterniflorum, and $R$. aquatilis at intermediate ranges, and $P$. alpinus, $P$. berchtoldii and $R$. trichophyllus at high ranges. However, values differed among studies and, in general, Pyrenean macrophytes displayed the lowest values for optimum conductivity ranges. Macrophytes in Welsh (Seddon, 1972) and Finnish lakes (Toivonen and Huttunen, 1995) presented intermediate values, and macrophytes in North Ireland lakes held the highest ones (Heegaard et al., 2001). Those differences could result from interspecific interactions, whereby aquatic macrophyte species accommodate their optima and tolerance range to minimize competition, as suggested by Pip (1984). Moreover, differences in geographical variables like altitude and latitude can also play a crucial role in driving the occurrence of aquatic macrophytes, as shown by Pulido et al. (2012b) when comparing different geographical areas.

\section{Predictive models and lake management}

Logistic models allowed us to estimate optimum ranges, to quantify the relative importance of the environmental variables and to determine the minimum set of variables required to predict macrophyte occurrence. However, the goodness of fit of multiple regression models, and therefore the uncertainty around predicted probabilities of occurrence, varied highly among species. In general, submerged macrophytes, such as $R$. aquatilis, $M$. alterniflorum, $C$. palustris, $P$. alpinus and $P$. berchtoldii, which interact strongly with the water column, were modeled more successfully (high $\mathrm{D}^{2}$ adj and low $\mathrm{C}-\mathrm{V}$ ) than isoetid species, which take up virtually all of their $\mathrm{CO}_{2}$ and inorganic nutrients via the roots from the sediment (Madsen and Sand-Jensen, 1991). $S$. angustifolium, with floating leaves, was the least predictable species. The inclusion of other variables, such as sediment characteristics or water current will be explored in future studies, since these could improve the prediction for some of the aquatic macrophytes as shown in Pulido et al. (2012b) where latitude, water alkalinity, pore water $\mathrm{PO}_{4}{ }^{3-}$ and sediment redox were the combination of variables that best correlated to vegetation composition in NW European soft-water lakes.

The occurrence of most species (9 out of 11) was predicted equally well by two or more multiple regression models (Akaike weight $<1$ in Tab. 3 and Supplementary Tab. 3). This reflects uncertainty in model definition and some degree of redundancy among candidate explanatory variables. Importantly, it warns us against overinterpreting the significance of individual predictors as proximate environmental constraints on aquatic macrophyte occurrence. Statistical models offer us a glimpse into the ecological niche of species, but the selected environmental variables may only be indirectly related to macrophyte development, as we recognize for the role of altitude. Statistical models are no substitute for experimental investigations, yet they give us rich information that can be checked against more detailed field studies. More pragmatically, they provide a tool for the prediction of species distribution in soft-water lakes, which was one of the goals in our study. Candidate sets of selected models can be used in two ways. Firstly, they allow us to select the models of more general applicability by choosing those with predictors that are less costly to obtain or more readily available. Secondly, they can be used together to produce predictions that incorporate modeling uncertainty through ensemble modeling (Araújo and New, 2007; Beale and Lennon, 2012).

Our results can assist managers in making conservation, management and restoration decisions, especially in those lakes devoid of macrophytes which lack records of their macrophyte population and in which species introduction may be necessary due to isolation or lack of recruitment. In addition, they may help to minimize the effort required to monitor and manage aquatic macrophytes, and are a step forward toward the prediction of future scenarios under global change (i.e., changes in climate and in atmospheric deposition). However, we recognize that the models we present here are limited by the amount of data, especially for the rarest species, and also they are strictly niche-based and take into account only independent responses of species to abiotic environmental factors. Our models could be improved in several ways. First, it may be important to incorporate the landscape position of lakes and their 
connectivity through surface waters, because dispersal limitation of spores, seeds and propagules may be an important driver of macrophyte distribution in high mountain lakes. Secondly, the distribution of species is likely not independent. Whereas some macrophytes occur spatially segregated in individual lakes, others tend to appear together, suggesting that the presence of one species may provide a niche for another (Gacia et al., 2009). For instance, it is common to find together in the same vegetation unit $S$. angustifolium, $S$. aquatica and $I$. echinospora or M. alterniflorum, $P$. berchtoldii and/or $P$. alpinus (Gacia et al., 2009).

\section{CONCLUSIONS}

Among the candidate factors, presence of macrophytes in Pyrenean lakes was best predicted by altitude, $\mathrm{NO}_{3}^{-}$, $\mathrm{SO}_{4}{ }^{2-}$ and catchment vegetation type. Lakes at low altitude, in vegetated catchments and with low water concentration of $\mathrm{NO}_{3}{ }^{-}$and $\mathrm{SO}_{4}{ }^{2-}$ are suitable to host the most common macrophytes in the Pyrenees. With regards to individual species, conductivity and $\mathrm{pH}$ were the most important environmental variables determining the distribution of individual macrophyte species in these soft-water lakes. The logistic regression models developed here have proved to be useful tools for understanding the response of individual macrophyte species to environmental variables. The results of this study allow us to predict the probability of occurrence of common macrophyte species in Pyrenean soft-water lakes, and may therefore be used for conservation and restoration purposes especially when species reintroduction is necessary due to isolation or lack of recruitment.

\section{ACKNOWLEDGEMENTS}

Financial support was provided by the Spanish Ministry of Science and Innovation through funding of the AQUAREST project (ref: OAPN 212/2010). We are grateful to Institut Cartogràfic de Catalunya (ICC) for providing GIS data. We also thank Dr. Guillermo de Mendoza for useful suggestions on earlier versions of the manuscript.

\section{REFERENCES}

Abeli T, Barni E, Siniscalco C, Amosso C, Rossi G, 2012. A cost-effective model for preliminary site evaluation for the reintroduction of a threatened quillwort. Aquat. Conserv. 22:66-73.

Araújo MB, New M, 2007. Ensemble forecasting of species distributions. Trends Ecol. Evol. 22:42-47.

Arts GHP, 2002. Deterioration of atlantic soft water macrophyte communities by acidification, eutrophication and alkalinisation. Aquat. Bot. 73:373-393.

Bañares Á, Blanca G, Güemes J, Moreno JC, Ortiz S, 2010. [Atlas y Libro Rojo de la Flora Vascular Amenazada de
España. Adenda. Dirección General de Medio Natural y Política Forestal (Ministerio de Medio Ambiente, y Medio Rural y Marino)].[Book in Spanish]. Sociedad Española de Biología de la Conservación de Plantas: 170 pp.

Barko JW, Smart RM, 1981. Comparative influences of light and temperature on the growth and metabolism of selected submersed freshwater macrophytes. Ecol. Monogr. 51: 219-235.

Beale CM, Lennon JJ, 2012. Incorporating uncertainty in predictive species distribution modelling. Philos. T. R. Soc. B 367:247-258.

Brouwer E, Roelofs JGM, 2001. Degraded softwater lakes: Possibilities for restoration. Restor. Ecol. 9:155-166.

Camarero L, Catalan J, 1993. Chemistry of bulk precipitation in the central and eastern Pyrenees, northeast Spain. Atmos. Environ. A-Gen. 27:83-94.

Camarero L, Catalan J, Boggero A, Marchetto A, Mosello R, Psenner R, 1995. Acidification in high mountain lakes in Central, Southwest, and Southeast Europe (Alps, Pyrenees). Limnologica 25:141-156.

Camarero L, Rogora M, Mosello R, Anderson NJ, Barbieri A, Botev I, Kernan M, Kopáček J, Korhola A, Lotter AF, Muri G, Postolache C, Stuchlík E, Thies H, Wright RF, 2009. Regionalisation of chemical variability in European mountain lakes. Freshwater Biol. 54:2452-2469.

Catalan J, Ballesteros E, Gacia E, Palau A, Camarero L, 1993. Chemical composition of disturbed and undisturbed highmountain lakes in the Pyrenees: a reference for acidified sites. Water Res. 27:133-141.

Catalan J, Barbieri MG, Bartumeus F, Bitušík P, Botev I, Brancelj A, Cogălniceanu D, Manca M, Marchetto A, Ognjanova-Rumenova N, Pla S, Rieradevall M, Sorvari S, Štefková E, Stuchlík E, Ventura M, 2009. Ecological thresholds in European alpine lakes. Freshwater Biol. 54: 2494-2517.

Catalan J, Camarero L, Gacia E, Ballesteros E, Felip M, 1994. Nitrogen in the Pyrenean lakes (Spain). Hydrobiologia. 274:17-27.

Catalan J, Vialta R, Pigem C, Aranda R, 1997. [Les obres hidràuliques en els Pirineus: avaluació, correcció i prevenció de l'impacte mediambiental].[Book in Spanish]. ENHER, FECSA, Fundació La Caixa: 552 pp.

Chappuis E, Ballesteros E, Gacia E, 2011a. Aquatic macrophytes and vegetation in the Mediterranean area of Catalonia: patterns across an altitudinal gradient. Phytocoenologia. 41:35-44.

Chappuis E, Gacia E, Ballesteros E, 2011b. Changes in aquatic macrophyte flora over the last century in Catalan water bodies (NE Spain). Aquat. Bot. 95:268-277.

Chappuis E, Gacia E, Ballesteros E, 2014. Environmental factors explaining the distribution and diversity of vascular aquatic macrophytes in a highly heterogeneous Mediterranean region. Aquat. Bot. 113:72-82.

Egertson CJ, Kopaska JA, Downing JA, 2004. A century of change in macrophyte abundance and composition in response to agricultural eutrophication. Hydrobiologia 524:145-156.

Gacia E, Ballesteros E, 1994. Production of Isoetes lacustris in a Pyrenean lake: seasonality and ecological factors involved in the growing period. Aquat. Bot. 48:77-89. 
Gacia E, Ballesteros E, 1996. The effect of increased water level on Isoetes lacustris L. in Lake Baciver, Spain. J. Aquat. Plant Manage. 34:57-59.

Gacia E, Ballesteros E, Camarero L, Delgado O, Palau A, Riera JL, Catalan J, 1994. Macrophytes from lakes in the eastern Pyrenees: community composition and ordination in relation to environmental factors. Freshwater Biol. 32:73-81.

Gacia E, Chappuis E, Lumbreras A, Riera JL, Ballersteros E, 2009. Functional diversity of macrophyte communities within and between Pyrenean lakes. J. Limnol. 68:25-36.

Heegaard E, Birks HH, Gibson CE, Smith SJ, Wolfe-Murphy S, 2001. Species-environmental relationships of aquatic macrophytes in Northern Ireland. Aquat. Bot. 70:175-223.

Lacoul P, Freedman B, 2006. Relationships between aquatic plants and environmental factors along a steep Himalayan altitudinal gradient. Aquat. Bot. 84:3-16.

Lee K, Isenhart HTM, Schultz RC, 2003. Sediment and nutrient removal in an established multi-species riparian buffer. J. Soil. Water Conserv. 58:1-8.

Liu C, White M, Newell G, 2011. Measuring and comparing the accuracy of species distribution models with presenceabsence data. Ecography 34:232-243.

Madsen TV, Sand-Jensen K, 1991. Photosynthetic carbon assimilation in aquatic macrophytes. Aquat. Bot. 41:5-40.

Mooij W, Hülsmann S, De Senerpont Domis L, Nolet B, Bodelier PE, Boers PM, Pires LM, Gons H, Ibelings B, Noordhuis R, Portielje R, Wolfstein K, Lammens ERR, 2005. The impact of climate change on lakes in the Netherlands: a review. Aquat. Ecol. 39:381-400.

Mosello R, Lami A, Marchetto A, Rogora M, Wathne B, Lien L, Catalan J, Camarero L, Ventura M, Psenner R, 2002. Trends in the water chemistry of high altitude lakes in Europe. Water Air Soil Pollut. 2:75-89.

Murphy KJ, 2002. Plant communities and plant diversity in softwater lakes of northern Europe. Aquat. Bot. 73:287-324.

Ninot JM, Batllori E, Carrillo E, Carreras J, Ferré A, Gutiérrez E, 2008. Timberline structure and limited tree recruitment in the Catalan Pyrenees. Plant Ecol. Divers. 1:47-57.

Olsen KR, Andersen FØ, 1994. Nutrient cycling in shallow, oligotrophic Lake Kvie, Denmark. Hydrobiologia 275276:255-265.

Peeters, ETHM, Gardeniers JJP, 1998. Logistic regression as a tool for defining habitat requirements of two common gammarids. Freshwater Biol. 39:605-615.

Pip E, 1984. Ecogeographical tolerance range variation in aquatic macrophytes. Hydrobiologia 108:37-48.

Pip E, 1988. Niche congruency of aquatic macrophytes in central North America with respect to 5 water chemistry parameters. Hydrobiologia 162:173-182.

Pulido C, Keijsers DH, Lucassen ECHET, Pedersen O, Roelofs JGM, 2012a. Elevated alkalinity and sulfate adversely affect the aquatic macrophyte Lobelia dortmanna. Aquat. Ecol. 46:283-295.

Pulido C, Sand-Jensen K, Lucassen ECHET, Roelofs JGM, Brodersen KP, Pedersen O, 2012b. Improved prediction of vegetation composition in NW European soft-water lakes by combining location, water and sediment chemistry. Aquat. Sci. 74:351-360.

R Core Development Team, 2012. R: A language and environment for statistical computing. Vienna, Austria.

Rascio N, 2002. The underwater life of secondarily aquatic plants: some problems and solutions. Crit. Rev. Plant. Sci. 21:401-427.

Risgaard-Petersen N, Jensen K, 1997. Nitrification and Denitrification in the Rhizosphere of the Aquatic Macrophyte Lobelia dortmanna L. Limnol. Oceanogr. 42:529-537.

Schindler DW, Curtis PJ, Parker BR, Stainton MP, 1996. Consequences of climate warming and lake acidification for UV-B penetration in North American boreal lakes. Nature 379:705-708.

Schuurkes JAAR, Kok CJ, Den Hartog C, 1986. Ammonium and nitrate uptake by aquatic plants from poorly buffered and acidified waters. Aquat. Bot. 24:131-146.

Seddon B, 1972. Aquatic macrophytes as limnological indicators. Freshwater Biol. 2:107-130

Segarra-Moragues JG, Catalan P, 2011. Characterization of microsatellite loci in Festuca gautieri (Poaceae) and transferability to $F$. eskia and $F$. × picoeuropeana. Am. J. Bot. 98:360-362.

Sommaruga-Wograth S, Koinig KA, Schmidt R, Sommaruga R, Tessadri R, Psenner R, 1997. Temperature effects on the acidity of remote alpine lakes. Nature 387:64-67.

Toivonen H, Huttunen P, 1995. Aquatic macrophytes and ecological gradients in 57 small lakes in southern Finland. Aquat. Bot. 51:197-221.

Van den Berg MS, Joosse W, Coops H, 2003. A statistical model predicting the occurrence and dynamics of submerged macrophytes in shallow lakes in the Netherlands. Hydrobiologia 506-509:611-623.

van Nes EH, Scheffer M, van den Berg MS, Coops H, 2003. Charisma: a spatial explicit simulation model of submerged macrophytes. Ecol. Model. 159:103-116.

Wagenmakers EJ, Farrell S, 2004. AIC model selection using Akaike weights. Psychon. Bull. Rev. 11:192-196. 